\title{
Surgical Treatment of Extravasation Injuries
}

\author{
PIETRO NAPOLI, MD, ${ }^{1}$ * BARTOLO CORRADINO, ${ }^{1}$ GIUSEPPE BADALAMENTI, $\mathrm{MD}^{2}{ }^{2}$ \\ MASSIMILIANO TRIPOLI, MD, ${ }^{1}$ SALVATORE VIENI, $M{ }^{3},{ }^{3} \mathrm{M}$. FABIO FURFARO, $\mathrm{MD}^{2}{ }^{2}$ \\ ADRIANA CORDOVA, ${ }^{1}$ AND FRANCESCO MOSCHELLA ${ }^{1}$ \\ ${ }^{1}$ Chirurgia Plastica e Ricostruttiva, Dipartimento di Discipline Chirurgiche ed Oncologiche, \\ Università degli Studi di Palermo, Italy \\ ${ }^{2}$ U.O. di Oncologia Medica, Dipartimento di Discipline Chirurgiche ed Oncologiche, \\ Università degli Studi di Palermo, Italy \\ ${ }^{3}$ Chirurgia Oncologica, Dipartimento di Discipline Chirurgiche ed Oncologiche, \\ Università degli Studi di Palermo, Italy
}

\begin{abstract}
The authors present their experience of treating anti-cancer drug extravasation by means of a composite surgical technique that consists of infiltration with physiological solution and hyaluronidase and subsequent manual aspiration of solutes alternated with profuse irrigation of the infiltrated area. In the immediate post-op we carry out a medical therapy that consists of calciparine and topic antibiotic and/or steroid creams. Since the year 2000 this technique has been used on 25 patients. We have had neither complications nor scars.

J. Surg. Oncol. 2005;91:264-269. (c) 2005 Wiley-Liss, Inc.
\end{abstract}

KEY WoRDs: extravasation injury; antiblastic; prevention; treatment

\section{INTRODUCTION}

In the last few years, due to an increase in the use of various chemotherapeutic protocols, we have seen a directly proportional increase in extravasation injuries.

An "extravasation injury" is usually damage caused by accidental leakage of solutions from the vein to the surrounding tissue spaces. The administration of chemotherapeutic antiblastics involves problems of toxicity that we do not usually have when dealing with other drugs.

Chemotherapeutic antiblastics aim at the destruction of cells. This therapeutic objective is both difficult to evaluate and irreversible. Moreover, the treatment is not selective as regards neoplastic cells so that we can easily understand what damage it can cause to neighboring tissues.

Extravasation injuries are among the most dangerous toxic effects of chemotherapy and they should be avoided and prevented rather than treated. This is both because local damage is often serious and because there are no specific treatments.

Infiltration of the drug in the subcutaneous tissue can cause damage which can span from light erythema to serious necrosis. The symptoms of extravasation injuries which a patient can notice are burning, pain, or intense paraesthesia which are localised where the infiltration took place. Other symptoms include reddening, inflammation, swelling, and edema.

Medical literature abounds in works on this topic; nonetheless there is not a univocal protocol to treat extravasation injuries yet $[1,2]$. That is the reason why different treatments have been used-including topic hypothermia, infiltration of physiological solution, hyaluronidase, cortisone creams, antidotes, and even surgical excision of the ulcer [3-8].

It is worth stressing that, on the basis of different case reports, in oncological patients who are being submitted to chemotherapy the incidence of extravasation injuries varies between $0.5 \%$ and $22 \%$. However, there is a constant increase of $1 \%-2.5 \%$ every year which perhaps is also due to an increase in the use of chemotherapy in several oncological protocols.

Prof. Francesco Moschella is a Director of Chirurgia Plastica e Ricostruttiva; Prof. Nicola Gebbia is a Director of U.O. di Oncologia Medica; Prof. Mario Adelfio Latteri is a Director of Chirurgia Oncologica; Bartolo Corradino is a Researcher; Adriana Cordova is an Associate Professor.

*Correspondence to: Dr. Pietro Napoli, MD, Via G. D’Annunzio 10, 90017 Santa Flavia (PA), Italy. Fax: +39 0916553720.

E-mail: pietronapoli@libero.it; chirplas@unipa.it

Accepted 18 February 2005

DOI $10.1002 /$ jso. 20248

Published online in Wiley InterScience (www.interscience.wiley.com). 
Local damage varies depending on the following parameters:

- Type of drug-vesiculating, exfoliating, irritating or neutral,

- Quantity of infused drug,

- Area of the infiltration.

Some factors can cause bigger damage; among them it is worth remembering high osmolarity treatments and treatments in which the drug can precipitate or closely bind to cellular structures like DNA, RNA, microtubules.

For the sake of convenience, in order to better devise treatment, antiblastic drugs are divided into four groups on the basis of their potential capacity to cause damage to tissues when extravasation injuries arise:

1. Vesiculating: these drugs can provoke serious cell damage or destroy tissues (necrosis). They cause bad and prolonged pains, fibrosis, and loss of mobility (Fig. 1).

2. Exfoliating: these are drugs that can cause cell damage and destruction of the skin tissue; redness and marked swelling are often immediately apparent, desquamation develops and progresses to ulcer formation.

3. Irritating and inflammatory: these drugs, when extravasated, can provoke pains, inflammation, flare reaction, including redness, either in the area where they are infused or along the vessel, or ulceration and rare destruction of the tissues.

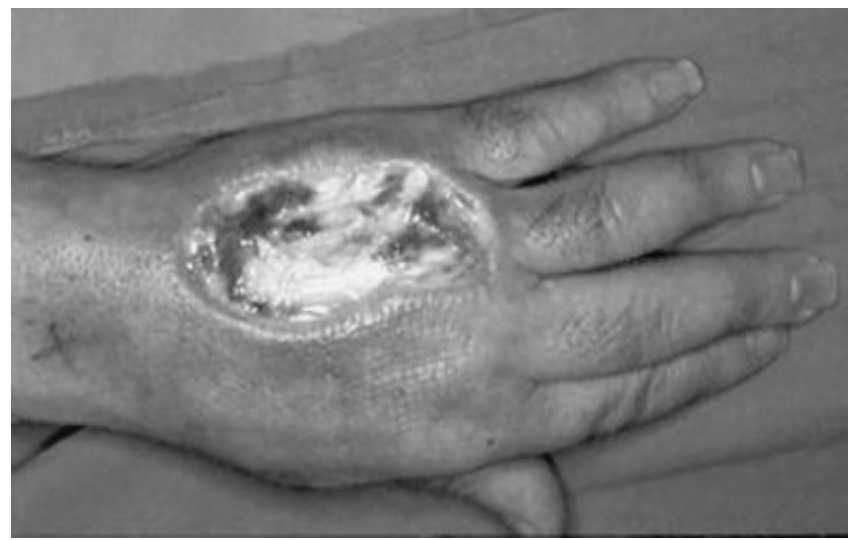

Fig. 1. Necrosis 14 days after untreated epirubicin extravasation on the dorsum of the hand of a 65 -year-old man.

4. Neutral: neither inflammatory nor irritating.

As already mentioned, this distinction is made purely for convenience purposes. Hence we had better consider each episode of extravasation injury as significant and worth paying attention to, whatever the drug that provoked it is.

Nowadays, vesiculating antiblastics are the most dangerous and also the most used injectable substances (see Table I). Among them there is dexorubicin which together with other antraciclin drugs is surely one of the most feared vesiculating drugs because of its capacity to bind to adipose tissue and, above all, to combine itself

TABLE I. Classification of Antiblastic Drugs on the Basis of the Potential Tissue Damage They can Cause

\begin{tabular}{llll}
\hline $\begin{array}{l}\text { Vesiculating: } \\
\text { Group 1 }\end{array}$ & \multicolumn{1}{c}{$\begin{array}{c}\text { Exfoliating: } \\
\text { Group 2 }\end{array}$} & $\begin{array}{c}\text { Irritating and inflaming: } \\
\text { Group 3 }\end{array}$ & $\begin{array}{l}\text { Neutral: } \\
\text { Group 4 }\end{array}$ \\
\hline Amsacrine & Aclarubicin & Carboplatin & Asparaginase \\
Carmustine & Cisplatin & Etoposide & Bleomicine \\
Dacarbazine & Liposomal daunorubicin & Irinotecan & Cladribine \\
Dactinomicine & Docetaxel & Teniposide & Cyclophosphamide \\
Daunorubicin & Liposomal Doxorubicin & Phosphate etoposide & Cytarabine \\
Doxorubicin & Floxuridine & 5-Fluorouracil & Edroclomab \\
Epirubicin & Mitrozantrone & Methotrexate & Fludarabine \\
Idarubicin & Oxaliplatin & & Gemcitabine \\
Melphalan & Topotecan & & Ifosfamide \\
Mitomicin & & & Pentostatin \\
Mustine & & & Rituximab \\
Paclitaxel & & & Thiotepa \\
Streptozocin & & & Beta-interferon \\
Treosulfan & & & Aldesleukin (IL-2) \\
Vinblastine & & & \\
Vincristine & & & \\
Vindesine & & & \\
Vinorelbine & & & \\
\hline
\end{tabular}


with the DNA in the complex DNA-topoisomerasis II, to block the synthesis of both DNA and RNA and to provoke cell death. Other dangerous substances are vincristin, cisplatin, and vinblastin. All of them at first provoke severe local inflammation then, after a few days, tissue ulceration and necrosis.

This article is about our experience of the use of a conservative surgical protocol combined with a medical treatment which consists of dilution and aspiration of the extravasated solute by means of abundant irrigation of the infiltrated area. Moreover, we will group various aspects with the aim of finding the right protocol to follow when dealing with extravasation injuries caused by antiblastic drugs [9-13].

Our aim is to evaluate the advantages of this treatment as regards functional and scar outcomes and also the oncological patient's quality of life.

\section{SURGICAL TECHNIQUE}

Our surgical protocol contemplates four stages:

\section{Infiltration}

2. First aspiration

3. Washout/irrigation

4. Second aspiration

First of all, this technique contemplates infiltration of saline solution in subcutaneous tissues where the extravasation injury is. This operation must be carried out as soon as possible after the accidental event has occurred.

The treatment starts by administering intradermic or subcutaneous local anaesthetic (Ropivacain $7.5 \%$ ) and hyaluronidase (Jaluran ${ }^{\circledR}<600$ UI). Obviously, the quantity to be injected is directly proportional to the area to treat and to tissue tension (Fig. 2). During this stage the aim is to dilute the extravasated drug in order to make aspiration easier. With the scalpel (Fig. 3), some small holes in the skin are created $(8-10)$. Through them some subcutaneous tunnels are created to aspirate the liquid by means of lipoaspiration cannulas measuring $2 \mathrm{~mm}$ (Fig. 4). Of course, the noble underlying structures should always be respected (superficial vessels, nervous fascicles, tendons).

Then, through the skin holes, we carry out a second infiltration of saline solution which varies between 500 and 3,000 $\mathrm{ml}$-depending on the area-and serves as an abundant irrigation (Fig. 5). This infiltration is followed by another aspiration.

The skin holes are never sutured (Fig. 6); they are just medicated with antibiotic cream and vaselined gauze. Soft, compressive bandage will then favor further liquid drainage by means of imbibition and capillarity.

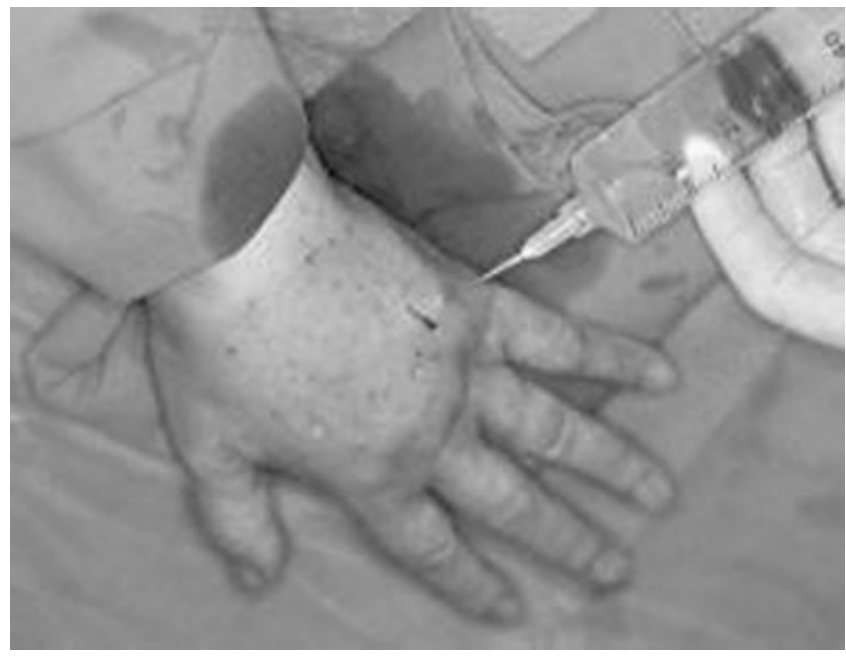

Fig. 2. Infiltration of hyaluronidase and physiological solution.

When extravasations injuries take place in the back of the hand this must be treated with particular carefingers are separated by means of gauze in order to avoid maceration. In the immediate post-op the anti-declivous position is advised. Finger mobilization is encouraged in order to favor drainage. In the post-op stage we administer low dose calciparine (0.3 U.I.) for 2-3 days and wide-spectrum antibiotics (cephazoline).

Post-op oedemas disappear after $24-40 \mathrm{hr}$ and the skin holes heal in 4-8 days. We have seen that it is better to remove and dilute as much extravasated solute as possible, preferably within $36 \mathrm{hr}$.

We just carry out hyaluronidase infiltration on patients who come to us after $48 \mathrm{hr}$ with oedemas or inflammation or a flush. By contrast, when no clear clinical signs are present, we do not carry out any treatment but we see the patient every day for the first week.

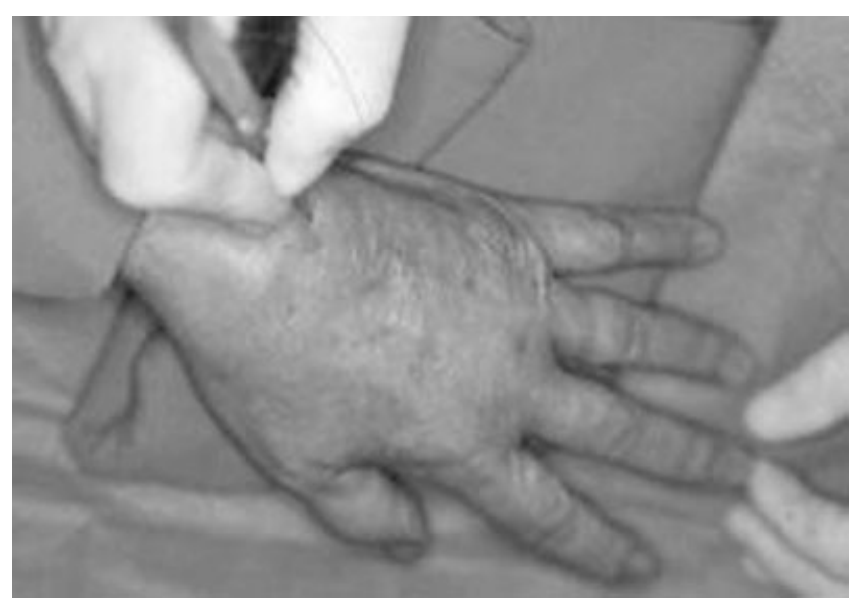

Fig. 3. A 62-year-old woman suffering from doxorubicin extravasation. The skin holes were done by means of a no. 11 scalpel. 


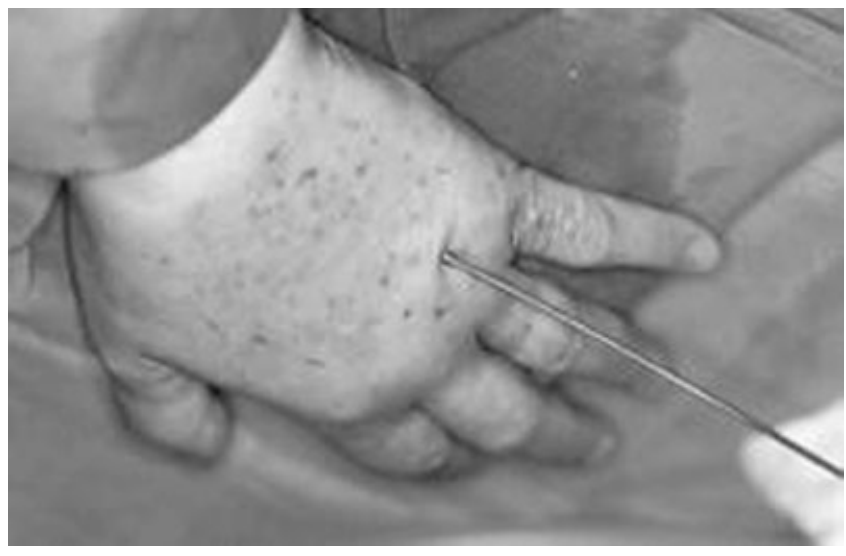

Fig. 4. Tunnelling by means of a $2 \mathrm{~mm}$ cannula. Aspiration of the injected liquid.

\section{MATERIALS AND METHODS}

Our case report is made-up of 25 oncological patients that-from January 2000 to date-came to us within $36 \mathrm{hr}$ of the traumatic event. Fifteen of the patients are women, while 10 are men whose age ranges between 29 and 72 years (average age 58 years). Presumably, the quantity of extravasated liquid varied between 10 and $35 \mathrm{~mm}^{3}$.

The time gap which elapsed between the extravasation and its treatment varies between $100 \mathrm{~min}$ and $36 \mathrm{hr}$.

The most affected areas are the hand back, the wrist volar fold, the elbow fold, the anti-cubital fossa, the forearm, and the arm bicipital groove (this is because in the absence of Implantable Systems - port-a-cath—either the medial and lateral veins of the forearm-cephalic and basilic - or the veins on the back of the hand are cannulated).

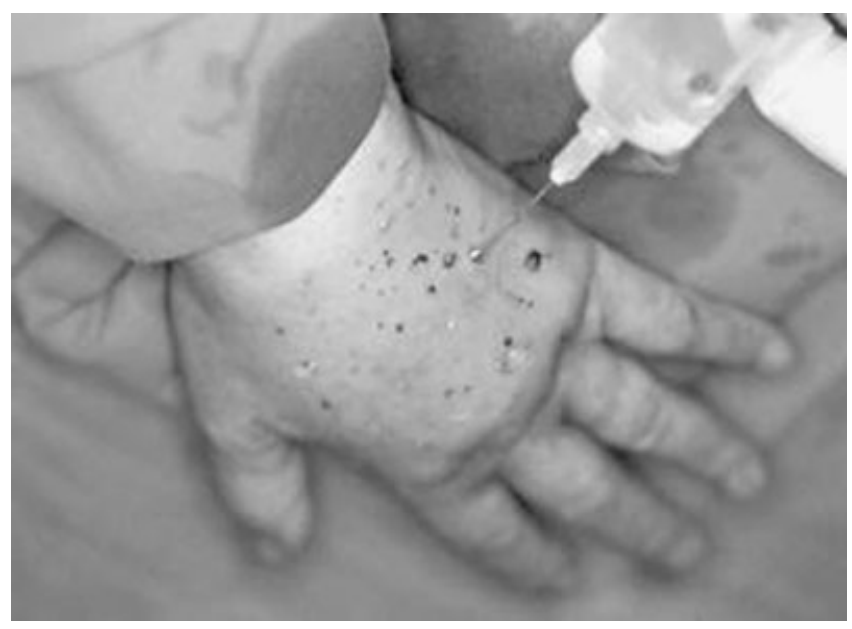

Fig. 5. Saline flush-out of the extravasation site.

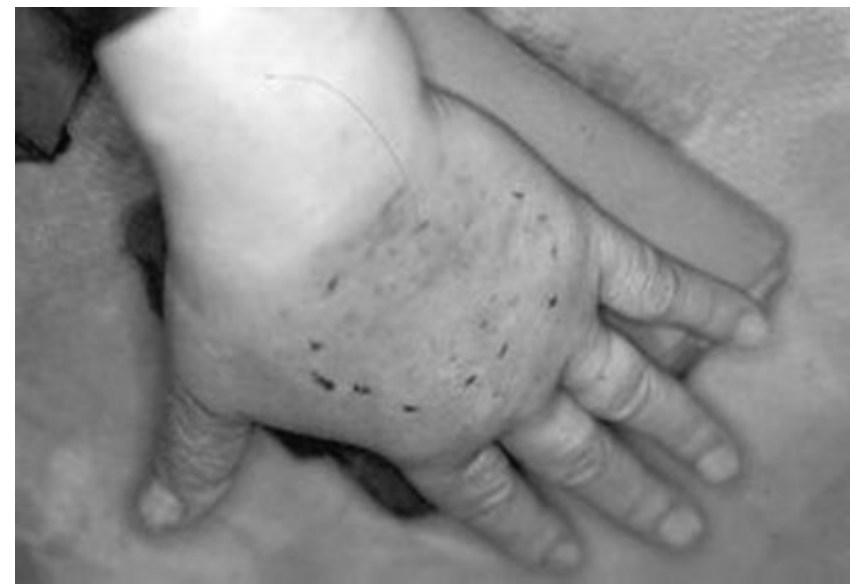

Fig. 6. Immediate post-op.

The follow-up varies between 8 months and 4 years, 16 months on average. During the observation period we did not see infections, haematomas, excessive bleeding, skin paraesthesias, scar retractions, or other significant complications apart from very small hyperpigmented areas and one temporary oedema which in any case healed in a few weeks.

Patients who were treated within a few hours did not have any inflammation and healed faster. No patients had difficulty in moving their fingers or wrists. Functionality was preserved and we did not notice any skin ulcerations or damage to soft tissues (Fig. 7).

\section{DISCUSSION AND CONCLUSIONS}

Extravasations of antiblastic chemotherapeutic drugs are fortuitous and unpredictable events. Of course, there are various more or less invasive treatments to choose

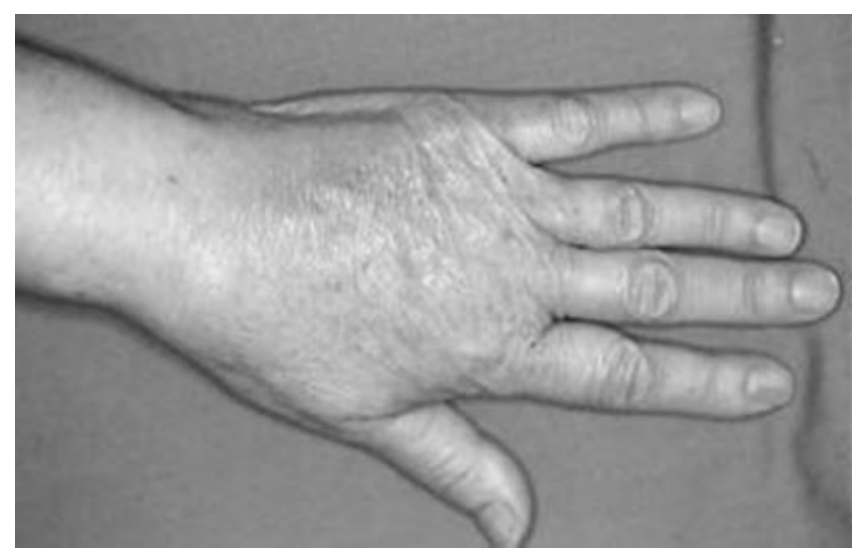

Fig. 7. Result after 1 month. 
from but they must be carefully considered in relation to each case. The possibility of developing effective antidotes may help treat this pathology in future.

Sodium bicarbonate, dimetilsulfoxid (DMSO), and glucocorticoids have been and are still used. They are certainly useful but they cannot always be administered and are not always effective.

By contrast, according to F. R. Heckler's [10] and J. J. Disa's [7]studies, the hyaluronidase enzyme seems to be very useful. It dissolves the binding of hyaluronic acid in tissues and expands the intra-tissue space thus creating a wider surface for dilution and for drug aspiration.

We would like to stress that treatment should be started as quickly as possible.

This technique is particularly useful for extravasations of vesiculating and exfoliating antiblastics (see Table I) and when the quantity of extravasated drug is equal or above $10 \mathrm{cc}$.

When dealing with extravasations caused by chemotherapeutic antiblastic vesiculating, exfoliating, and irritating drugs we do not agree with the "wait and see" protocol because of high risk of progressively worse ulcerations and necrosis which often, apart from the skin, affect the surrounding soft tissues provoking irreversible damage.

Moreover, the administration of local anaesthetic does not involve particular side effects in oncological patients.

Extravasation injuries should be considered as oncological medical-surgical emergencies to be treated immediately (within a few hours rather than days) if we want to limit damage and prevent those severe and disfiguring ulcerations which lack of treatment can provoke.

\section{REFERENCES}

1. Larson DL: What is the appropiate management of tissue extravasation by antitumor agents? Plast Reconstr Surg 1985;75:397.

2. Treatment of extravasation injury. The National Extravasation Information Service. On URL: http://www.extravasation.org.uk

3. Lambert F, Couturaud B, Arnaud E, et al.: Extravasations iatrogènes de solutes cytotoxique ou hyperosmolaires. Prise en charge thèrapeutique. Encycl Med Chir-Chirurgie plastique reconstructive et esthetique, 1999;5:45-149.

4. Cichetti S, Jemec B, Gault DT: Two case reports of vinorelbine extravasation: Management and review of the literature. Tumori, 2000;86:289-292.

5. Scuderi N, Onesti MG: Antitumor agents: Extravasation, management, and surgical treatment. Ann Plast Surg 1994;32:39-44.

6. Laurie SWS, Wilson KL, Kernahan DA, et al.: Intravenous extravasation injuries. The effectiveness of hyaluronidase in their treatment. Ann Plast Surg 1984;13:191-194.

7. Disa JJ, Chang RR, Mucci SJ, et al.: Prevention of adriamycininduced full thickness loss using hyaluronidase infiltration. Plast Reconstr Surg 1998;101:370-374.

8. Sommer NZ, Bayati S, Neumeister M, et al.: Dapsone for the treatment of doxorubicin extravasation injury in the rat. Plast Reconstr Surg 2002;109:2000-2005.

9. Dorr RT: What is the appropriate management of tissue extravasation by antitumor agents? (Discussion). Plast Reconstr Surg 1985;75:403.

10. Heckel FR: Current thoughts on extravasation injuries. Clin Plast Surg 1989;16:557.

11. Vandeweyer E, Heymans O, Deraemaecker R: Extravasation injuries and emergency suction as treatment. Plast Reconstr Surg 2000;105:109-111.

12. Casanova D, Bardot J, Magalon G: Emergency treatment of accidental infusion leakage in the newborn: Report of 14 cases. Brith J Plast Surg 2001;54:396-399.

13. Burd DAR, Santis G, Milward TM: Severe Extravasation injury: An avoidable iatrogenic disaster? Br Med J 1985;290:1579-1580.

\section{COMMENTARY}

Extravasation injury is a well-known adverse event associated with intravenous chemotherapy administration and occurs when drugs escape from the veins, catheters or ports into subcutaneous tissues. The systematic use of central access catheters and ports has drastically reduced the incidence of these complications, although they still occur apparently at the rate of about $0.1 \%-6 \%$ in patients receiving systemic chemotherapy. The local reactions are often distinguished into irritant and vesicant reactions. The irritant-type are self-limited phlebitis and erythematous reaction along the vein or at the site of administration. The reaction by vesicants is often described as chemical cellulitis, which initially presents in a similar way to irritation but may worsen to result in tissue necrosis. A large number of non-surgical treatments have been attempted such as cold application and elevation of the affected area with limited success, as well as local injection of steroids, sodium bicarbonate, sodium thiosulfate, hyaluronidase, and $\beta$-adrenergic agonists and antagonists. Local application of DMSO has been tried with some evidence that DMSO protected from ulceration.

Systemic Dexrazoxane, an agent cardio-protective from the effects of anthracycline has been found to

DOI 10.1002/jso.20252

Published online in Wiley InterScience (www.interscience.wiley.com). 